\title{
Impact of technical trainings on socio-economic status and knowledge to farmers for the management YMV and charcoal rot diseases of soybean by antagonistic microorganism and chemical pesticides
}

\author{
S. R. Sharma*, V. K. Singh ${ }^{1}$, O.M. Gupta ${ }^{2}$ and D. P. Singh ${ }^{3}$ \\ Krishi Vigyan Kendra (JNKVV), Stationganj, Narsinghpur (M.P.) India \\ (Email: srsharma_srsgkp@rediffmail.com)
}

\begin{abstract}
On the basis of Socio Economic Status of farmers records, technical trainings to Farmers and knowing the constraints of farmers faced during last years, an experiment was conducted in the year 2017 and 2018 Kharif season with four soybean verieties namely JS 20-29, JS 97-52, RVS 2001-4 and JS20-69 in four replications with control plot. Personal contact with farmers indicated that majority of farmers $(60 \%)$ came under small land holders categories having only 3.0 ha cultivated area whereas $13.33 \%$ farmer occupied $>10$ ha cultivated areas considered large land holding farmers. More than $57 \%$ young farmers having age below 35 years seriously engaged in agricultural work than old age ( $>50$ years) whose interest was $26.66 \%$ followed by middle age groups ( $35-50$ years). As for as educational level was concerned, $56 \%$ respondents were of medium category having education between $10^{\text {th }}$ to higher secondary. Nearly $29 \%$ respondents had high qualification (Graduate and above) level while $14 \%$ were of low educational level. Majority of respondents (78\%) was engaged in Agricultural enterprise followed by horticulture ${ }^{+}(14.64 \%)$ and dairy $(6.66 \%)$. Incidence of both diseases was also varied from variety to variety of soybean. Highest incidence of yellow mosaic disease was found in RVS2001-4(8.79\%) followed by JS20-29 (5.57\%) and JS97-52 (2.32\%) whereas no incidence was observed in JS 20-69. It was observed that YMV affected plant either unable to bear the flowers and fruits (pods) or very few pods appear but dried prematurely. Results revealed that RVS2001-4 affected maximum (14.15\%) with charcoal rot infection than JS2029 in comparison to JS97-52 whereas minimum incidence was recorded in JS20-69. Control plot affected more severely than demonstration and it was due to none application of trichoderma in seed and soil treatment. Among the soybean entries JS 2069 gave more yield (17.39q/ha ) followed by RVS2001-4 (14.57q/ha) in compassion to JS20-29 and JS97-52).Timely application of bioagent and chemical pesticides for seed/soil treatment plus spray and change of knowledge through technical training to the farmers during crop period play an important role in managed the diseases and enhanced the soybean productivity. The ratio of yield increased was $15.73 \%$ to $32.04 \%$ over control. A training was organized after harvested of the crop to know the major constraints and observed that 94.66 per cent respondents were face difficulties recording lack of knowledge for identification of beneficial and damager pests followed by unavailability of quality bio-pesticides $(93.33 \%)$ such as trichoderma, NPV, Bavaria basiyana and bio-fertilizers $(81.33 \%)$ at local level for pests and diseases management. Besides above problems, unavailability of trained labours (78.66\%), quality seed (68\%), rate of wages and problems of storage were also the important and time needed constraints.
\end{abstract}

Key Words : Soybean variety, Trichoderma, Thiomethaxam, Farmers profile, Trainings, Constraints

\footnotetext{
* Author for correspondence :

${ }^{1}$ Deportment of Plant Pathology, Bada Agriculture University, Bada (U.P.) India

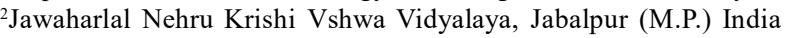

${ }^{3}$ Jawaharlal Nehru Krishi Vishwa Vidyalaya (KVK), Panna (M.P.) India
} 